\title{
BREVE HISTÓRICO DA PSICOLOGIA ESCOLAR NO BRASIL
}

\author{
Brief History Of School Psychology In Brazil
}

\author{
Aline Ottoni Moura Nunes de Lima ${ }^{1}$
}

\section{Resumo}

Este artigo foi elaborado a partir de uma revisão bibliográfica sobre o tema e enfoca as tendências da relação psicologia e educação ao longo da história, a partir de uma perspectiva sociocrítica. Pretende contribuir na reflexão sobre as possibilidades de atuação em psicologia educação escolar sinalizando para o fato de que as construções científicas em psicologia repercutem nas práticas pedagógicas. Por uma questão didática, dividimos nosso texto em reflexões sobre quatro modelos de atendimento psicológico em contextos educativos escolares. Partimos de um modelo de atendimento psicométrico, analisando o pano de fundo social sobre o qual ele foi construído, seus objetivos ideológicos, a repercussão da teoria no mundo e na educação. Em seguida, apresentamos os modelos clínico e preventivo construídos sob a influência da psicanálise que, apesar de mudar a visão sobre a origem das diferenças atuais, não provocaram mudanças significativas na visão sobre as dificuldades educacionais e por sua vez no contexto concreto da escola. Para finalizar apontamos algumas características de um fazer psicológico escolar crítico, que tem como objetivo realizar, juntamente com os atores que compõem o cenário pedagógico e da escola, mudanças que gerem a possibilidade de que a escola cumpra seu papel social de possibilitar a todos que por ela passarem a apreensão dos saberes construídos pela humanidade ao longo tempo.

Palavras-chave: Psicologia Educacional; História; Tendências.

\section{Abstract}

This article originated from a bibliographical revision and focuses on the trends in school psychology throughout history, from a social perspective. It intends to contribute on the reflection about the possibilities of performance in the field of school education psychology, noting the fact that the scientific knowledge in psychology resound in the pedagogical practices. For a matter of didactics, the text is divided in reflections about four models of psychological care in school environments. The research started from a model of psychometric care, analyzing the social background it was built upon, its ideological goals and the repercussion of the theory in the world and in education. Then, clinical and preventive models built under the influence of psychoanalysis were presented and, although they alter the point of view on the origin of individual differences, they did not cause significant changes in the perspective about educational difficulties nor in the solid context of school. In the end, the author points out some characteristics of a conscious schoolbased psychological work, which has the goal of making, along with the members of the school scenario, changes that generate the possibility for the school to fulfill its social role of making possible for all the students to apprehend the knowledge gathered by mankind throughout time.

Keywords: Psychology, Educational; History; Trends.

1 Professora substituta de Psicologia da Educação Escolar na Universidade Federal de Uberlândia. Psicóloga Especialista em Psicologia Escolar: Processos de Aprendizagem e de Escolarização pela USP. -

Endereço para contato: Rua Acre, 941 B. Umuarama, Uberlândia - MG. CEP: 38402-022.

E-mail: aottoni@yahoo.com.br 
"A compreensão do texto, a ser alcançada por sua leitura crítica, implica a percepção das relações entre o texto e o contexto".

(Paulo Freire)

Este artigo é uma versão modificada do primeiro capítulo de monografia apresentada ao Instituto de Psicologia da Universidade de São Paulo (USP) ${ }^{2}$ como parte dos requisitos para 0 título de especialista em Psicologia Escolar: processos de aprendizagem e de escolarização. Pretendemos fazer um levantamento histórico da relação da psicologia com a educação desde o seu início.

A importância e a atualidade deste tema se justificam porque somente quando analisamos retrospectivamente como a psicologia respondeu ao longo de sua história, enquanto ciência, ao chamado da educação, é que podemos entender o significado da participação dos psicólogos na escola atualmente e vislumbrar possibilidades de atuações alternativas àquelas que se tornaram hegemônicas.

No Brasil, conforme nos alerta Goulart (2003), foi a Psicologia que derivou da Psicologia da Educação. Esta, desde o início do século passado, tem sido chamada pela educação para fundamentar teoricamente questões importantes da educação escolar, se constituindo no primeiro campo de aplicação daquela ciência. No entanto, Loureiro (1997) denuncia que apesar das explicações oferecidas pela psicologia para os problemas pelos quais passa o sistema de ensino brasileiro, não se vêem mudanças significativas ao longo dos anos.

A partir de várias questões levantadas a respeito das explicações oferecidas pela psicologia aos problemas da educação, faz-se urgente uma postura comprometida com as preocupações da comunidade educativa escolar que, vinculando teoria e prática, possam, como propõe Coll (2000), contribuir para a compreensão e melhoria das práticas em contextos educativos concretos, o que precisa ser realizado levando-se em conta a necessidade de adotar posturas ideológicas e morais.

Para que possamos efetivar uma prática consciente, que leve em conta as desigualdades sociais e seus efeitos na escolarização de nossas crianças e jovens, é preciso compreender o nosso estar no mundo, situando-nos historicamente. Sen- do assim, segundo Patto (1984), “a análise da constituição histórica e da essência da psicologia científica é imprescindível, pois nos permitirá entender mais a fundo o significado de sua participação nas escolas...".

Neste artigo, faremos um breve relato para relembrarmos como, ao longo da história, vem se dando a relação da psicologia com a educação. Delineando os caminhos e des-caminhos dos psicólogos a partir de uma visão hegemônica clínica até chegarmos a uma perspectiva crítica de psicologia escolar.

Então, o que vinha fazendo o psicólogo escolar desde o final do século XIX, marco de ligação da psicologia com a educação? Por uma questão didática, dividimos nosso texto em quatro modelos com base em posturas de atendimento psicológico nos contextos educativos escolares, mas não podemos tomá-las como se fossem sendo substituídas uma pela outra. Coll (2000) nos confirma que ainda hoje há influências desses modelos no trabalho de psicólogos e pedagogos responsáveis pela elaboração de políticas educacionais. Passamos à apresentação sucinta de cada um dos modelos.

\subsection{0 modelo psicométrico - medindo, cla ssificando, segregando...}

A psicologia adquiriu seu status científico em 1879 com a inauguração do Laboratório de Psicologia em Leipzig, na Alemanha, por Wilhelm Wundt. Este médico, fisiologista, interessava-se por desenvolver estudos sobre a psicofisiologia dos processos mentais, ou seja, sobre os processos elementares da consciência. Seu estudo “(...) apresenta-se como o marco que ensejou o estudo do comportamento humano sob a ótica das ciências físicas e biológicas, desconsiderando os estados subjetivos na compreensão do homem e suas relações" Yazlle (1990).

Wundt foi precedido por Francis Galton (1822-1911) que, em 1869, publicou sua obra "Hereditary Genius" como início de seu projeto eugenista, baseando-se na obra "A Origem das Espécies" de seu contemporâneo e parente, Charles Darwin. A partir daí, realizou vários trabalhos em seu laboratório de psicometria, no University College

2 Orientadora: Professora Doutora Elenita de Rício Tanamachi; ano de conclusão, 2001. 
de Londres, tendo como objetivo principal medir a capacidade intelectual e provar a determinação hereditária das aptidões humanas, para que fosse possível selecionar os mais capazes, aprimorando a espécie humana.

O período pós - revolução industrial, com a vitória da burguesia liberal, é o pano de fundo sobre o qual Galton desenvolveu sua teoria. Num contexto em que a burguesia emergente reafirmava seu poder tendo como base o liberalismo, pautado num ideal de igualdade de oportunidades para todos, as diferenças entre classes sociais eram concebidas a partir da explicação de que uns eram mais capazes do que outros, recebendo respaldo nos instrumentos de medida de inteligência e personalidade criados por Galton.

A primeira escala métrica de inteligência infantil foi desenvolvida por Binet, na França em 1905. "Sua passagem (...) para o laboratório de pedagogia experimental, (...) foi um passo decisivo na constituição do primeiro método em psicologia escolar, do qual até hoje não se libertou: a psicometria" (Patto, 1984). Tinha como objetivo desenvolver instrumentos que possibilitassem a seleção, adaptação, orientação e classificação de crianças que necessitassem de educação escolar especial em normais e anormais.

Houve repercussão desse estudo em todo o mundo. As escolas européias e as localizadas na América do Norte adotaram os testes, que estavam sendo estudados em larga escala, e com eles, as conseqüências pedagógicas que deles advêm, como, por exemplo, a divisão de crianças em grupos homogêneos, separação em normais e anormais e uma seleção do que seria ensinado a cada um deles.

Enquanto isso, suas colônias européias lutavam pela introdução dessa nova "moda educacional" em suas escolas. Por volta de 1906, no Rio de Janeiro, Manoel Bonfim fundou o Laboratório de Pedagogia Experimental, planejado por Binet (Paris), junto ao Pedagogium, órgão fundado a fim de incentivar melhorias educacionais, que se transformou em um centro de cultura superior, em 1897. Em um estudo sobre a história da psicologia brasileira, encontramos um relato sobre 0 ensino da psicologia nas escolas normais, no século XIX, que demonstra a influência européia e norte-americana na sociedade brasileira.

Massimi (1990) aponta que, para formar um corpo docente competente e adequado quanto às necessidades do sistema educacional brasi- leiro, as escolas normais procuram elaborar e instruir seus alunos em uma metodologia científica do ensino, inspirada nos modelos europeus e norte-americanos.

Patto (1984) traz a informação de que “(...) a primeira função desempenhada pelos psicólogos junto aos sistemas de ensino, (...) no Brasil, (...), foi a de medir habilidades e classificar crianças quanto à capacidade de aprender e de progredir pelos vários graus escolares".

A influência das idéias do movimento psicométrico, na atuação dos psicólogos no Brasil, fica notória, segundo Yazlle (1997, na apreciação da tese para ingresso na Escola Normal de Recife, de Ulisses Pernambucano, em 1918, intitulada "Classificação de Crianças Anormais".

Essa postura é segregadora, pois, na medida em que categorizamos as crianças e jovens, estamos excluindo-os da possibilidade de vivenciar o processo educacional regular e corremos o risco de, segundo Machado (1994, p. 63), aprisionar a diferença num sistema negativo, comparativo.

Esses trabalhos trouxeram de positivo 0 início de um movimento pioneiro de assistência a crianças excepcionais, ao qual, mais tarde, se engajaria a psicóloga e educadora Helena Antipoff, chegada ao Brasil em 1929.

\subsection{0 modelo clínico: saúde $x$ doença... diagnosticando...}

No início do século XX, as produções em Psicologia cresciam aos borbotões e os estudos de Sigmund Freud (1856-1939) sobre a psicanálise vieram mudar a visão a respeito da origem das diferenças pessoais. Com a elaboração de uma teoria que considerava a relação do indivíduo com o grupo familiar determinante da personalidade (que se forma ao longo do processo de desenvolvimento) e, por sua vez, de como este indivíduo se posicionará no mundo, lançava-se um questionamento oportuno para a visão do inatismo.

A psicanálise foi trazida para o Brasil pelos médicos que, por sua vez, foram os primeiros a produzir conhecimentos psicológicos neste país. Nas faculdades do Rio de Janeiro e da Bahia, dá-se uma introdução ao modelo clínico de psicologia escolar, inspirado na medicina, cujo objetivo era psicodiagnosticar e tratar crianças que apresentassem problemas de aprendizagem. 
É importante salientar qu, no Brasil, mesmo com a adoção da teoria psicanalítica como base teórica para explicação dos problemas de aprendizagem, muitos foram os estudos que continuaram utilizando os parâmetros de normalidade para classificar as crianças. $\mathrm{O}$ que temos de novo é que as crianças anteriormente classificadas como anormais são, a partir de agora, denominadas crianças problema.

Segundo Moysés e Collares (1992), o neurologista americano Strauss, em 1918, "lança a hipótese de que os distúrbios de comportamento (...) e os de aprendizagem poderiam ser conseqüentes de uma lesão cerebral mínima”. Teoria que só se legitimou efetivamente a partir da década de 60 do séc. XX e que, até hoje, além de influenciar as práticas psicológicas e educacionais que pretendem classificar crianças como normais e anormais, continua dando margens a pesquisas.

\subsection{0 modelo preventivo: antecipando, clinicando...}

Com o advento da psicanálise e, com ele, de novas explicações que situavam os problemas de aprendizagem nas influências ambientais, mais especificamente no desajuste familiar e, concomitante ao processo de biologização do comportamento, que favorece a patologização destes, tinhase um terreno fértil para a disseminação da prática psicológica de psicoterapia e orientação familiar, frente a problemas de aprendizagem e a atribuição de rótulos.

Isto se deu num contexto socioideológico caracterizado pelo período pós-Primeira Guerra, quando a "sociedade aristocrática rural, (...) entrava para a fase de industrialização brasileira, enquanto projeto social de modernização", Yazlle, (1997). A maioria da população não tinha acesso à escola e, portanto, não estava qualificada para o mercado de trabalho.

Surgiu o Movimento de Higiene Mental (década de 20 e 30 do século XX), com funções preventivas de orientação, assistência, pesquisa e ensino de técnicos especializados em desajustamentos infantis. Esse movimento partia do princípio de que o profissional de Psicologia deveria se adiantar aos problemas e cuidar do controle do bem-estar social e individual da nação. Era necessário que as crianças fossem qualificadas para se conquistar o ideário do Estado Novo de industrialização.

Essas práticas psicoeducacionais ainda estão presentes nos dias de hoje em muitas instituições de ensino no nosso país, e têm sido denunciadas por vários autores, direta ou indiretamente. Pode-se vê-las nos Serviços de Orientação Educacional e Psicologia Escolar, por meio de atendimentos individuais aos alunos frente a questões que dizem respeito ao cotidiano escolar, em encaminhamentos a psicopedagogos de crianças com problemas de aprendizagem, etc.

Temos exemplos de práticas reveladoras da postura clínica no ambiente escolar, de caráter especialmente adaptacionista, que situa o problema no aluno ou, quando mais camuflada, desloca o foco para o professor. Herança que recebemos de uma psicologia exercida no início do século $\mathrm{XX}$, quando “(...) a escola, seus procedimentos e objetivos não eram objeto de questionamento, nem mesmo enquanto variáveis que poderiam gerar problemas de aprendizagem e de ajustamento" (Patto, 1984).

\subsection{0 modelo compensatório: novas explicações, velhas posturas...}

No Brasil, a partir da década de 70 do séc. $\mathrm{XX}$, chegaram as idéias produzidas nos Estados Unidos, que constituíam a Teoria da Carência Cultural. Essa teoria surgiu diante da necessidade de se conter as tensões geradas pelos movimentos reivindicatórios das minorias raciais. Compunhase de diversos trabalhos que explicavam "a discrepância de rendimento escolar observada entre as crianças dos vários níveis sócio-econômicos" (Souza, 1997).

De acordo com esse conjunto de idéias, as crianças de segmentos sociais pobres em recursos financeiros não possuem as mesmas aptidões para 0 aprendizado que as de classe privilegiada e, portanto, precisam aprender com recursos diferentes dos oferecidos aos outros. Os ambientes em que vivem geram deficiências nutricionais, perceptivo-motoras, cognitivas, emocionais e de linguagem e ainda são vítimas da desestruturação familiar incapaz de fornecer uma base segura para a vida da criança.

Diante dessa explicação, foram realizados Programas de Educação Compensatória, voltados 
para as crianças carentes, primeiro nos Estados Unidos e depois no Brasil. "(...) disseminando a crença de que todos os esforços estão sendo empenhados no sentido de escolarizar os filhos da pobreza e sanar suas deficiências" (Patto, 1984).

Com a consideração das diferenças culturais, percebe-se uma tentativa da Psicologia em considerar os aspectos sociais dos "problemas de aprendizagem", mas ainda havia desconsideração das dimensões ideológicas presentes na teoria em voga, o que não provocou mudanças de postura em psicologia escolar.

Segundo Patto (1984), o psicólogo realizava um trabalho voltado para o diagnóstico das deficiências dos carentes mediante testes psicológicos, detectando suas incapacidades e buscava, juntamente com outros profissionais de educação, programar meios psicopedagógicos que possibilitassem a aprendizagem das crianças.

O psicólogo passou a assumir a função técnica, coerente com a antiga clínica, por seu caráter individualizante, de assessoria aos professores, aqueles que "não sabem". Essa perspectiva aparece claramente em textos como o de Reger, que define o objetivo básico do psicólogo escolar: “(...) ajudar a manter a qualidade e a eficiência do processo educacional através da aplicação dos conhecimentos psicológicos (...) enquanto educador comprometido com a identidade do acadêmico, o psicólogo escolar pode tentar ensinar outros profissionais no sistema escolar" (Reger, 1989).

É importante esclarecer que, mesmo ao atender o grupo de professores, o psicólogo está adotando neste momento histórico uma postura individualizante, por não estar considerando ainda todo o cenário educativo escolar, mas apenas um de seus componentes.

A merenda escolar e os grupos de reforço de aprendizagem, os materiais produzidos para a estimulação precoce de crianças pré-escolares e as Escolas Municipais de Educação Infantil foram medidas adotadas a fim de "solucionar o problema da dificuldade de escolarização das crianças e adequá-las melhor às exigências da escola" (Souza, 1997). Estas, entre outras, são algumas heranças deste modo de entendimento dos problemas de aprendizagem.

Não é sem motivo que as dificuldades escolares que causam o fracasso têm sido freqüentemente atribuídas a características individuais das crianças: “(...) a psicologia encobre o papel cum- prido pela instituição de reproduzir no âmbito da distribuição dos bens culturais a desigualdade característica da distribuição dos bens materiais" (Loureiro, 1997).

A psicologia sempre se fez presente na educação, principalmente criando critérios para classificar as crianças que não estavam adaptadas aos padrões ideais estabelecidos pela classe social dominante, nos diferentes períodos históricos. Os rótulos que atribuiu a elas mudaram de nome durante toda a história. Se num primeiro momento as separou em normais e anormais, num segundo modelo de trabalho, as denominou crianças problema, e diante do modelo que por hora abordamos, marca os deficientes ou os carentes.

\subsection{Uma introdução ao modelo crítico}

Foi a partir da década de 1980 do século $\mathrm{XX}$ que se iniciou um movimento de análise crítica da atuação do psicólogo escolar, a fim de que fosse possível a consideração dos processos desenvolvidos na instituição escolar. Os "problemas de aprendizagem" passaram a ser vistos como um fenômeno complexo, constituído socialmente, cuja análise deve abarcar os aspectos históricos, econômicos, políticos e sociais.

A base teórico-filosófica da teoria crítica constitui-se no Materialismo Histórico dialético formulado por Karl Marx. Torna-se fundamental, neste momento, ressaltarmos que o marxismo não é uma teoria já superada. Meira (2000) nos fala sobre a atualidade dessa perspectiva, ressaltando a presença do período histórico analisado por Marx, o capitalismo.

Nesta perspectiva, o homem é visto como um ser que, a partir da sustentação biológica que nos constitui como seres humanos, tem nas relações sociais de que tomam parte ao longo do tempo a possibilidade de se construir juntamente com outros homens, na medida em que constrói as formas de satisfação de suas necessidades numa relação dialética.

Bock (1997) acrescenta que, para os psicólogos que adotam uma postura sócio-histórica, o fenômeno psicológico é também construído a partir das relações do homem numa topografia e sociedade específicos num momento histórico específico. 
A educação e, mais especificamente, a educação escolar são compreendidas como instâncias fundamentais no processo de socialização do conhecimento produzido pela humanidade.

E, por conseguinte, as relações escolasociedade devem ser "pensadas por contradição", no sentido de que "se o fato educativo é um politikum e um social, conseqüentemente, é também verdadeiro que toda situação política e social determina sensivelmente a educação" (Manacorda, 1989 apud Tanamachi, 1997).

Quando analisamos o fenômeno educacional, é fundamental levarmos em conta que a realidade educacional é determinada por múltiplos fatores. Ao psicólogo é lançado o desafio de superar a visão técnica/clínica que sempre embasou sua atuação, passando a atuar politicamente, ou seja, "atuar e refletir politicamente com os indivíduos para conscientizar-se junto com eles das reais dificuldades da sua sociedade" (Freire, 1983).

O rompimento com o modelo clínico de atuação implica, conforme Ragonesi (1997), entre outras coisas, em romper com a separação entre as atividades de ensino que seriam responsabilidade do professor e o comportamento dos alunos, que por sua vez seriam responsabilidade do psicólogo. Assim conseguiremos "situar mais adequadamente os processos psicológicos no interior do processo pedagógico, garantindo a especificidade de nossa atuação, a partir de uma reflexão sobre 0 lugar da Psicologia na Educação", sem reduzir uma à outra.

O momento é de criar espaços de reflexões com todos os grupos que fazem parte da escola, famílias e aluno, professores, pedagogos, funcionários e comunidade, considerando a realidade escolar como um todo, pesquisando temas que façam parte das preocupações dos envolvidos, fazendo parcerias com outros profissionais que têm a educação como foco de atenção.

Sabemos que não há um manual de atuação em psicologia crítica, o que temos é uma indicação de Souza (2000) de que o momento é de discussões e a construção-desconstrução da teoria e prática em psicologia escolar será constante e dialética. No entanto, temos alguns "princípios norteadores da prática".

A título de "considerações finais", gostaríamos de ressaltar que existe certo consenso entre os psicólogos educacionais sobre a necessidade de maior clareza sobre a nossa identidade e finalidade profissional. Segundo Patto (1997), o papel do psicólogo escolar está mal delimitado ainda e uma discussão aprofundada leva a uma discussão da sua própria formação. Meira (2000) alerta que no trabalho de formação do psicólogo escolar devemos estar sempre perguntando: qual deve ser o compromisso ético - político do psicólogo que queremos formar?

Quanto ao lugar ocupado pelo psicólogo escolar, Ragonesi (1997) nos diz que "o melhor lugar para o psicólogo é o lugar possível, seja dentro ou fora de uma instituição". O mais importante é que ele se insira na educação, assumindo um compromisso teórico e prático com as questões da escola, que é o seu foco de atenção.

Além disso, a autora acrescenta que é fundamental que os psicólogos que atuam diretamente na instituição escolar preocupem-se com a melhoria das práticas pedagógicas, garantindo que a escola utilize-se dos conhecimentos psicológicos na elaboração de suas propostas de trabalho, visando a atingir o objetivo primeiro da educação: a humanização.

É importante criar alternativas para uma atuação pautada no compromisso com o atendimento público, pautada no direito à cidadania, recuperando e assumindo como os teóricos do início do século XX, Vigotski, Wallon, Luria, Leontiev, etc, o discurso e as preocupações com o reformismo social.

Na construção da psicologia que elege a educação como objeto de reflexão e ação, é preciso subsídios teórico-práticos importantes que possibilitem a consolidação de um corpo de conhecimentos mais sólido que faça avançar, no interior da ciência psicológica, a compreensão sobre 0 processo de construção social do indivíduo e que permita que a educação possa construir novas práticas pedagógicas.

\section{Referências}

Bock, A. M. B. (2000). As influências do Barão de Münchhausen na Psicologia da Educação. In Tanamachi, E. R. \& Proença, M. \& Rocha, L. M. (orgs.) Psicologia e Educação: desafios teórico-práticos. (pp.11-34). São Paulo: Casa do Psicólogo.

Coll, C. (2004). Concepções e tendências atuais em psicologia da educação. In Cool, C., \& Marche- 
si, A. \& Palácios, J. Desenvolvimento Psicológico e Educação. Porto Alegre: Artmed.

Freire, P. (1983) Educação e Mudança. São Paulo: Paz e Terra.

Goulart, I. B. (1989) Psicologia da Educação: Fundamentos Teóricos e Aplicações á Prática Pedagógica. Petrópolis: Vozes.

Loureiro, M. C. S. Psicologia escolar: mera aplicação de diferentes psicologias à educação? In M. H. S. Patto. Introdução à psicologia escolar. (pp. 449-458). São Paulo: Casa do Psicólogo.

Massimi, M. (1990). História da Psicologia Brasileira: da época colonial até 1934. São Paulo: EPU.

Meira, M. E. M. (2000) Psicologia Escolar: Pensamento Crítico e Práticas Profissionais In E. de $\mathrm{R}$. Tanamachi, \& M. Proença, \& M. L. Rocha (org), Psicologia e Educação: desafios teórico-práticos. (pp. 35-72). São Paulo: Casa do Psicólogo.

Moysés, M. A. A., \& Collares, C. A. (1992) A história não contada dos distúrbios de aprendizagem. Caderno Cedes, 28, 31- 48.

Patto, M. H. S. (1984) Psicologia e Ideologia: uma introdução crítica à Psicologia Escolar. São Paulo: T. A Queiroz.
Patto, M. H. S. (1997) O papel social e a formação do psicólogo: contribuição para um debate necessário. In M. H. S. Patto (org.), Introdução à Psicologia Escolar. São Paulo: Casa do Psicólogo.

Ragonesi, M. E. M. M (1997). Psicologia Escolar: Pensamento crítico e práticas profissionais. Tese de Doutorado Não Publicada. Instituto de Psicologia, Universidade de São Paulo, São Paulo.

Reger, R. (1989) Psicólogo Escolar: educador ou clínico? In M. H. S. Patto (org), Introdução à Psicologia Escolar. São Paulo. T. A. Queiroz.

Souza, M. P. R. (1989 - julho/dezembro). A questão do rendimento escolar: mitos e preconceitos. Revista da Faculdade de Educação, 15, 188-201.

Tanamachi, E. de R. (1997) Visão crítica de Educação e de Psicologia: elementos para a construção de uma visão crítica de Psicologia Escolar. Tese de Doutorado Não Publicada, Universidade Estadual Paulista, Marília.

Yazlle, E.G. (1997) Atuação do Psicólogo Escolar: Alguns Dados Históricos. In B. B. B. Cunha (org.), Psicologia na Escola: um pouco de história e algumas histórias. São Paulo: Arte \& Ciência.

Recebido em/Received in: 18/05/2005 Aprovado em/Approved in: 23/05/2005 